\section{Medicine as poetry}

\author{
John Launer
}

Before I studied medicine, I did an English degree. It was at a time when cultural studies had not been invented and close reading of literary texts was still in fashion. There were a few books on this topic that were considered to be classics, and one of them was by a writer called William Empson. It had the title 'Seven Types of Ambiguity.' Empson was something of a legend because he had come up to Cambridge to study mathematics in the 1920s but changed to English literature, wrote the book aged 21 while still an undergraduate, and was then expelled without a degree after a servant found condoms in his college room. He subsequently became a scholar of Chinese literature and a poet of distinction in his own right, while leading a colourful personal life. The reason his book became a classic was because of the way he argued that great poetry depended not just on its capacity to express complex meaning but to convey several different meanings at the same time.

The seven types of ambiguity that Empson described in his book are not exhaustive. Instead, they represent points along a scale. At one end of this scale are straightforward devices like the use of metaphor, which is almost universal in poetry, and simply calls to mind an interesting comparison (for example, 'I wandered lonely as a cloud.') At the other end of the scale, there is the kind of writing that leaves readers having to make up their own minds entirely about what the author really means. The best known example of this is probably a novel by Henry James called 'The Turn of the Screw', where a children's governess describes events that are might be either real or imagined, and the author never resolves this uncertainty. In between these two extremes, Empson describes a range of other types of ambiguity. These include the striking use of opposites, word play, revealing slips of the pen, meanings that seem to have emerged in the writer's own mind during the process of writing, and unclear expressions that leave the reader to fill in the gaps.

Since changing to medicine, I have always taken an interest in the use of language in the consultation. However, I had

Correspondence to Dr John Launer, Faculty Development, Health Education North West London, Stewart House, 32 Russell Square, London WC1B 5DN, UK: john.launer@londondeanery.nhs.uk more or less forgotten about William Empson and his book until I recently came across a reference to it in an unexpected context-an essay on medical ethics, by the Australian physician Paul Komesaroff. $^{2}$ In contrast to almost everything ever written about communication skills, Komesaroff argues that ambiguity in medical conversations can be a valuable source of expanded understanding and new meanings. While scientists usually seek certainty, clarity and the elimination of divergent meaning, he suggests, clinical communication often requires 'the deliberate preservation of uncertainty.' Drawing on Empson and others including the philosopher Levinas, Komesaroff puts the case for respecting ambiguity in our use of language and developing its use. 'We rely on ambiguity', he writes, 'when we need to express new meanings, when we wish to give voice to new or difficult ideas: for example, when we are trying to discern the goals of treatment or to clarify an emotional response'.

\section{NATURE OF LANGUAGE}

Komesaroff is not arguing in favour of muddled expression and miscommunication. Instead, he sets out a more profound and sophisticated view of the nature of language than the one that dominates medical thinking, where one word or phrase is generally believed to represent only a single thing or idea. He points out how all effective communication has to start with a suspension of presuppositions, and a search for a way 'to break through the curtain of mutual uninitelligibility.' This means opening oneself to 'suggestiveness and allusiveness.' It involves the careful, tentative use of 'the same devices, rhetorical forms, figures and tropes generally eschewed by philosophers and scientists, but embraced by poets and creative writers.' Speech, he reminds us, 'is not a solitary or impersonal exercise or a thought, it is not a process of mediation among contested propositions; it is a shared adventure of creation and discovery'.

Reading the article by Komesaroff, and recalling the book by Empson after all these years, has brought to mind some occasions in clinical practice when my interactions with patients succeeded not because of medical knowledge, but through subtle exchanges of language, of the kind that both writers are describing.
For example, I remember a patient who came in saying: 'There are three things I want to see you about.' Something about her emphasis on the word 'three' led me to ask immediately: 'What's the fourth?' She told me. It was the most important problem on her mind, and we never needed to return to the others. Another patient, irate at something I had said to challenge him, called me a 'fat lot of use' and stormed out of the room. His comment drew attention to the fact I was overweight at the time, but it turned out to be accurate in other ways as well. Two weeks later, he returned to say he had thought about what I said and decided it was true and useful. More recently, a patient came to see me with a chronic skin condition, saying she felt like Job in the Bible, who was afflicted with with incurable boils. I asked why she chose that comparison, and she listed a catalogue of disasters in her life recently, including the loss of her job and home. We were then able to discuss how the Book of Job ends, with its hero restored to health and prosperity, and how 'the Lord blessed the latter end of Job more than his beginning'.

Such consultations do not take place every day-although elements of them may be present more often than we suspect. As Komesaroff suggests, they can happen at critical moments, or when the mismatch between the discourse brought by the patient and the standard one offered by doctors is so great that we are compelled to explore radical alternatives. I never kept a diary of such exchanges over the years, but now wish I had done so. I would certainly encourage students and trainees to look out for the times they manage to transcend the banal formulas of everyday medical conversations, and find themselves moving into similes, metaphors, allusions, puns, humour, paradox or other imaginative forms of speech. If they did so, they would discover that medicine can be poetic, in the true meaning of the word.

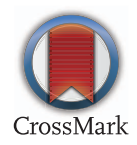

To cite Launer J. Postgrad Med J 2014;90:302.

Postgrad Med J 2014;90:302.

doi:10.1136/postgradmedj-2014-132703

\section{REFERENCES}

1 Empson W. Seven Types of Ambiguity. London, Chatto and Windus, 1930

2 Komesaroff P. Uses and misuses of ambiguity: Uses of ambiguity. Int Med J 2005;35:632-3. 